\title{
Positive and negative aspects of GRI reporting as perceived by Brazilian organizations
}

\author{
Thiago Ferreira Quilice ${ }^{1,2,5}$ (D) | Luciana Oranges Cezarino ${ }^{3}$ (i) | Marlon Fernandes \\ Rodrigues Alves $^{2,4}$ (D) | Lara Bartocci Liboni ${ }^{2}$ (D) | Adriana Cristina Ferreira Caldana2 (D)
}

\author{
${ }^{1}$ Federal Institute of Education, Science and \\ Technology of Minas Gerais, Management \\ Department, Ouro Branco, Brazil \\ ${ }^{2}$ University of São Paulo, School of Economics, \\ Business Administration and Accounting, \\ Ribeirão Preto, Brazil \\ ${ }^{3}$ Federal University of Uberlândia, Faculty of \\ Business and Management, Business Depart- \\ ment, Brazil \\ ${ }^{4}$ Federal Institute of Education, Science and \\ Technology of São Paulo, Management Depart- \\ ment, São Carlos, Brazil \\ ${ }^{5}$ Federal University of Minas Gerais, Depart- \\ ment of Administrative Sciences at the School of \\ Economics, Belo Horizonte, Brazil \\ Correspondence \\ Thiago Ferreira Quilice, Federal Institute of \\ Education, Science and Technology of Minas \\ Gerais, 90 Afonso Sardinha, Ouro Branco, Minas \\ Gerais, Brazil. \\ Email: thiagoquilice@hotmail.com
}

\begin{abstract}
This paper aims to identify the positive and negative aspects in the sustainability reporting framework proposed by the Global Reporting Initiative (GRI). The research was conducted through content analysis of 27 companies' responses to three questions: "Why does the company where you work prepare a sustainability report?" "What are the positive aspects you identify in the framework for GRI reporting?" and "What are the negative aspects you identify in the framework for GRI reporting?" The questionnaire was sent to all Brazilian companies that published sustainability reports using the GRI guidelines between 2011 and 2013 related to the base year 2010. We found that respondents viewed the GRI guidelines and the reports they created as management tools for sustainability and that they assist in benchmarking sustainability performance and legitimizing the sustainability actions of the organization. Furthermore, some respondents indicated that the reports themselves are marketing tools. On the other hand, the respondents reported difficulties in understanding the proposed GRI guidelines. They considered the guidelines complex, ambiguous, and too flexible, which undermined both the standardization of the reports and the ability to compare reports. Based on these comments, it is recommended that the GRI develop a simpler and less flexible reporting methodology.
\end{abstract}

\section{KEYWORDS}

Global Reporting Initiative, sustainability certification, sustainability performance, sustainability reporting

\section{I INTRODUCTION}

The practice of publishing sustainability-related reports is common in companies. Accordingly, a considerable number of organizations count on specific departments under the name of "sustainability" to publish practices relating to their management of the relationships between their businesses and society (Baumgartner \& Ebner, 2010; de Souza Campos et al., 2013).

Despite the relatively widespread practice of publishing sustainability reports, the models for the creation of such documents require continuous development and improvement. One such model is proposed by the Global Reporting Initiative (GRI), and although this model is used worldwide (de Souza Campos et al., 2013; KPMG, 2013), the guidelines have been the recipient of criticism (Isaksson \& Steimle, 2009; Morhardt, 2009).

Therefore, more research to analyze the GRI model for sustainability reporting is required, as those documents can bring to light the issues to improve corporate sustainable conduct. Studies within the available literature have pointed out that organizations have both positive and negative motivations to create sustainability reports. The positive motivations are linked to transparency and accountability (Fonseca, McAllister, \& Fitzpatrick, 2014), whereas the negative motivations tend to be linked to superficial aspects as enhancing an organization's image and decision-making direction sense, without substantive change (Gray \& Milne, 2002; Illingworth, 2004). No actual work analyzing the motivations of the managers in GRI reporting companies was found in the literature reviewed for this study. Our specific study performed a process-based view of the managers who work directly with the GRI reporting process inside organizations, and we present the results in this paper.

The differential of this work consists of identifying the reasons why Brazilian companies engage in reporting and both the positive and negative aspects in the GRI reporting worldwide model. The research is based on the opinions of employees who are responsible for engaging 
in sustainability reporting in companies adopting the practice of publishing reports. It is noteworthy that this study contrasts with others of a similar nature, which seek, among other things, to:

- Identify the importance of the report to various stakeholders (Moseñe, Burritt, Sanagustín, Moneva, \& Tingey-Holyoak, 2013),

- Measure the company's profits (Berthelot, Coulmont, \& Serret, 2012), or

- Analyze the type of information published (Samuel, Agamuthu, \& Hashim, 2013).

Moreover, few studies have used primary data for study of the GRI reports (Brown, De Jong, \& Levy, 2009; Futerra Sustainability Communications, KPMG, \& Sustainability, 2010). Arguably, most of those works rely on the analysis of the relationships between the characteristics of organizations (e.g., size, sector, profitability, country of origin) and the released information (e.g., number of reported indicators, report application level, quality of released information). During the literature review, we found only one work that was similar to this present paper in collecting and examining the opinions of those responsible for reporting on their businesses. That similar study was carried out by the KPMG (2013). Moreover, according to the referenced GRI study, questioning the reporting companies is crucial to understanding why they report their sustainability practices, as the practice of reporting will become widespread once companies identify which of their needs are met through reporting.

The main practical contribution of this study was to permit the employees responsible for sustainability reports to express their thoughts on why companies prepare sustainability reports. Furthermore, the positive and negative aspects perceived in the model proposed by the GRI are covered. The analyses herein can assist the reflection that takes place in academic circles on the subject of disclosure of sustainability practices and highlight key points to be improved in the GRI model, the most widely used reporting model.

\section{2 | SUSTAINABILITY REPORTS}

A very simple definition of what is a Corporate Social Responsibility (CSR) report, or sustainability report, coined by Gray, Owen, and Adams (1996), apud Dincer (2011), asserts that such documents represent the duty to be accountable regarding the activities for which one is responsible. According to Fifka (2013), sustainability reports originated in the 1970s and emerged as a new form of nonfinancial reports in the 1990s when modern corporations began receiving criticism and became susceptible to government regulations. According to Gray (2001), in an increasingly complex world, with even more powerful organizations, it was inevitable that groups in society should call for accountability to verify whether the power wielded by these organizations was duly accompanied by their respective responsibilities. Reynolds and Yuthas (2008) argue that there is a social contract between the company and its stakeholders, as if they were part of the company, and therefore, they have their own sets of demands regarding the management of the organizations and the communi- cation process. Notably, according to Lozano and Huisingh (2011), sustainability reports are a consequent evolution of the involvement of companies with sustainability issues, in addition to other support tools, such as life-cycle assessment and environmental management systems. Positive aspects are also described with the introduction of sustainability reporting frameworks, such as the GRI's, insofar as they helped organizations to increase their transparency and accountability on a number of social and environmental issues (Fonseca et al., 2014).

However, some authors have pointed to different views regarding reporting. To Caron and Turcotte (2009), the reporting process can be ambiguous. For example, if the reporting process is intended to show efforts to attain sustainability without being obliged to show any achievements, does the report functions as an "alibi" rather than as a description of serious work in progress? Moneva, Archel, and Correa (2006) postulate that companies can lose the big picture of sustainability when they report using the GRI guidelines. This practice can lead to flawed decision making (Aras \& Crowther, 2009; Mc Elroy, Jorna, \& Van Engelen, 2008). Deegan (2002) presents that in developing countries, companies are motivated to report for economic and image reasons more than for ethical or moral ones. In such cases, sustainability reporting is more a matter of seeking external legitimacy rather than functioning as an effective instrument for improving sustainability processes (Deegan, 2007). Existing business reporting models are inadequate, and using an excessively standardized process in an attempt to transform detailed and complex analyses of an organization's interactions with ecological systems, resources, habitats, and societies, and then interpreting these data in light of all other organizations' past and present impacts on those same systems is impossible (Gray \& Milne, 2002; Illingworth, 2004). Indeed, to Patten (2002), there is a negative relationship between performance and disclosure for sample firms.

\subsection{Global Reporting Initiative}

The GRI is a nongovernmental organization created in 1997 by the Coalition for Environmentally Responsible Economies and the United Nations Environment Programme. The organization seeks to promote the development of sustainability reporting by providing support and guidance in this task (GRI, 2012). The GRI reporting framework is quite comprehensive and includes guidelines for the measurement and dissemination of information on economic, environmental, and social performance.

The GRI report model is intended to help companies to measure their sustainability practices. It provides a fairly comprehensive framework for sustainability reporting, which shall be adopted by any company, ranging from small businesses to larger groups with diverse operations worldwide (GRI, 2011). The GRI report is divided, according to the triple bottom line concept, into economic, environmental, and social dimensions.

\section{3 | METHODS}

The present study delves into the motivations of organizations for engaging in sustainability reporting using the GRI guidelines as well as 
the positive and negative aspects of sustainability reporting as identified by the employees responsible for preparing the reports. Thus, the present study centers around answering the following three questions:

- Why does the company you work for prepare a sustainability report? (Motivations for reporting)

- What are the positive aspects in the GRI model?

- What are the negative aspects in the GRI model?

Thereafter, our challenge was to understand why, in the responding employees' opinions, their companies engage in sustainability reporting. To this end, the content analysis method was our approach of choice (Bardin, 2011). Employees and their contact information were identified in the GRI report specific to each company. The sample included all Brazilian organizations that have published a sustainability report for the base year 2010-the year with the highest number of reports filed with the GRI database-up to April 2013. During this time, 124 reports were registered. The sample was composed of respondents from companies reporting using the $\mathrm{G} 3$ version; the negative and positive aspects found in our analysis did not include the G4 updates.

For the assessment, a questionnaire was sent, via email, to all firms in the identified sample, asking which strengths and weaknesses were identified in the reporting model proposed by the GRI. It was up to the companies to indicate which aspects of the GRI reporting guidelines were positive or negative in light of their own organizational processes.

In addition to contact information, it was possible to obtain from the reports other information, such as the size and type of organization (e.g., private, partnership, nonprofit, subsidiary, state-owned, or public), whether it was traded on the stock market (listed or nonlisted), its sector of activity, and the level of application of the GRI report (A, $A+$, $\mathrm{B}, \mathrm{B}+, \mathrm{C}$, or $\mathrm{C}+$ ).

The questionnaires were sent out within the months of April and May 2013. The results from this emailing were as follows: 27 companies responded to the questionnaires; 87 companies did not respond; in six cases, the email addresses were invalid; and in four cases, the businesses were unable to respond because the professionals who would need to be making the responses were involved in other business processes. In view of the qualitative character herein, the amount of 27 respondents does not preclude the use of the content analysis technique. Notably, the composition of the types of respondent companies within the sample is similar to the initial sample.

Approximately $80 \%$ of the responding companies were classified in the GRI report as large firms, $10 \%$ as multinational, and $10 \%$ as smallor medium-sized firms. Furthermore, half of the responding companies were private, $20 \%$ were classified as partnerships, $10 \%$ as nonprofit, $10 \%$ as associations, and the rest were divided between state-owned and public companies. Forty-five percent were listed companies, 35\% were nonlisted companies (stock exchange for public trading), and the rest were not specified. The sample was concentrated in the energy utilities, financial services, and health services sectors.

The next step was to group the responses into categories according to the idea expressed in each response. As this study represents exploratory research, we chose to specify the categories of analysis retrospectively. Therein, given the shortness of the answers, it was decided not to use a content analysis software. Finally, the groups of responses were analyzed and discussed based on the scientific literature in the field.

\section{4 | RESULTS AND DISCUSSION}

This section is divided into three parts, analyzing each of the questions presented in the method section:

- Why does the company you work for prepare a sustainability report? (Motivations to report)

- What are the positive aspects in the GRI model?

- What are the negative aspects in the GRI model?

\subsection{Motivations to report}

We looked first at the reasons or motivations that caused organizations to undertake sustainability reporting.

\section{We looked first at the reasons or motivations that caused organizations to undertake sustainability reporting.}

\subsection{1 "Improving the company's image" category}

In this category, the responses were sorted into the following groupings:

- Displaying increased transparency,

- Achieving increased credibility, and

- Achieving increased market acknowledgement.

Displaying increased transparency conveys the objective of companies using their sustainability reports to present their management styles and what they have achieved in terms of economic, environmental, and social goals. According to Bebbington, Larrinaga, and Moneva (2008), the search for transparency stems from the need for legitimization in society. Chiefly, in Brazil, this need derives from the existing business culture, or reflects the manner in which a company is legally regulated (Legendre \& Coderre, 2013). In regard to this theory, Brazil nurtures the stakeholder-business culture, with the common view that the interests of stakeholders are as legitimate as those of shareholders. In addition, the country's legal system is based on the so-called Code Law (stakeholder model). Hence, companies shall bear social responsibilities beyond the objective of achieving economic efficiency. Under such conditions, companies should be more likely to legitimize their actions before society, an endeavor achievable via the publication of 
sustainability reports. However, Boiral (2013) argues that the reporting model proposed by the GRI allows companies to report the positive facts only, while omitting the negative information. Therefore, legitimacy with no real transparency would be possible, allowing the report to be turned into a mere device to simulate sustainable positioning. Likewise, based on the small number of people who read sustainability reports, the conclusions of Brown et al. (2009) endorse this understanding, observing that the release of the report per se should be enough to achieve legitimacy regardless of its contents.

Accordingly, "being transparent" was reported as a motivation by 10 companies, including nonprofits, publicly, and privately held, and large-, medium-, or small-sized businesses. Two companies pointed to "credibility" as a motivation, and only one of these two also reported "transparency," a large company classified as a subsidiary and public company. One firm (a large and privately held subsidiary) cited the motivation, "more recognition," without ever mentioning "being transparent," or "achieving credibility," along with other reasons closely related to improving internal management.

Although there is no evidence regarding the three items comprising this category, it can be understood that companies believe that by being transparent and engaging in good sustainability initiatives, they should accumulate credibility and market acknowledgement for their work. Nevertheless, transparency itself, without suitable sustainability actions, might result in low credibility and lack of recognition. In apparent contradiction, companies failed to relate increased transparency to more specific items, such as credibility and recognition or the search for legitimacy. The other responses from those organizations were more likely to relate to internal management, market trends monitoring, and relationships with stakeholders, which are more closely related to the company's performance in terms of sustainability. Hence, two conclusions arise:

1. The organizations would be more concerned with performance issues than with improved image, in opposition to Baumgartner and Ebner (2010), to whom sustainability in companies should be less related to strategic issues, and instead to coincidence of actions; or

2. Because of the criticism that the sustainability reports would be public relations tools only (Haigh \& Jones, 2006), companies were reluctant to answer such questions.

\subsection{2 | "Relationship with stakeholders" category}

This category includes the grouped responses under the theme "increased integration with their stakeholders" (e.g., publishing practices, understanding expectations, and improving management) with a respondent reporting, "Maintaining a more direct relationship with stakeholders," with three respondents reporting, and "dialogue with stakeholders" with two respondents reporting.

In analyzing this category, it is crucial to consider Utama (2011), who advised that considering stakeholders requires companies to provide information on sustainability. There is an information asymmetry between the company and the stakeholders, with companies disclosing convenient information only. The stakeholder cannot reward nor punish the most or least sustainable companies. In this sense, Utama (2011) proposes a reporting framework that includes four items:

- A report template that is globally accepted and that standardizes the information disclosed by companies;

- An audit standard globally accepted and that is used to ensure that the information disclosed can be trusted;

- Regulation by governments of the reporting regarding the sustainability practices; and

- Maintenance within companies of a corporate governance mechanism that has the function of defending the interests of all stakeholders, not just shareholders.

\section{There is an information} asymmetry between the company and the stakeholders, with companies disclosing convenient information only.

In regard to using a reporting model that allows comparisons among companies, Utama (2011) argued that the model proposed by the GRI comes closest of the reporting models to meeting such a goal. However, unlike financial reporting, the GRI reports do not include a summary that provides the reader with an overview of the company's sustainability performance (Utama, 2011). Moreover, it is noteworthy to consider the conclusions from the study, Reporting Change: Readers \& Reporters Survey 2010 (Futerra Sustainability Communications et al., 2010), sponsored by institutions associated to the GRI. Chiefly, in this report, the performance of companies in sustainability was not compared. Of more than 5,000 readers surveyed, scarcely $15 \%$ used the sustainability reports based on the GRI model to compare companies, with this percentage represented mainly by consultants conducting benchmarking or competitive analysis.

Therefore, in the view of Utama (2011), the report seems to be the tip of the iceberg in stakeholder care strategies. Thus, in this light, the respondent companies included in this category would not be effectively reaching their goal of integrating with stakeholders.

The responses pointed to the goal of actually incorporating stakeholders into their operational strategies. Brown et al.'s (2009) analysis of the GRI guidelines led them to two possible theories, one linked to the empowerment of civil society (private civil regulation) and the other linked to the management of social performance by investors and audit and consulting firms. However, neither of these theories, which are not opposed, although they may appear to be, is valid. The first is not valid because the strongest stakeholders had greater weight in determining the development of the GRI guidelines, thus disregarding a greater participation by the others. The second is not valid because the lack of standardization does not allow comparisons among 
companies, which would be of critical concern to investors and consultancies (Brown et al., 2009; Futerra Sustainability Communications et al., 2010).

Following this reasoning, the report under the GRI guidelines has become just one tool that allows organizations to manage sustainability, reputation, and brand (Brown et al., 2009), limiting the activities of stakeholders to discussions of materiality and points to be reported without a real dialogue among the parties.

\subsection{3 | "Initial public offering" category}

One company concluded that one of its motivations for preparing a sustainability report was its intention to open the company's capital, and that issuing the report would be part of the company's preparation process.

"Signaling theory," which argues that corporate sustainability reporting is a way to manage the reputational risk of an organization (Legendre \& Coderre, 2013), could explain this action, as the risk reduction would benefit potential investors in making decisions on an initial public offering. Carnevale and Mazzuca (2014) appear to confirm this concept, indicating that investors appreciate the reporting of information, perhaps because it should decrease information asymmetry.

Despite some scientific basis supporting the benefit of sustainability reporting to potential investors, there are contrary opinions, as well, including those identified by Boaventura, da Silva, and Bandeira-DeMello (2012). According to these authors, there is no evidence pointing to positive, negative, or neutral relationships between potential investors and sustainability reporting, and no consensus as to whether a company's social performance would affect its financial performance.

\subsection{4 "Contributing with other companies" category}

Three groups of respondents were identified as having this motivation. One such respondent was in the consultancy sector and prepared its sustainability report in response to customer demand. The second respondent was a large, privately held company, which had sustainability as a focus of its service-offering strategy. This second respondent viewed the practice of sustainability reporting as a way to share experiences and engage the market. The third respondent reporting this motivation was a small company that, as part of its mission, sought to encourage the adoption of sustainable practices. This third respondent replies that it uses sustainability reports as a means of disseminating knowledge, stating, "the CSR adoption was a natural way to the organization who understands how essential is disseminate knowledge and also be an application of what it spreads out" (from Authors' research survey).

These results are consistent with Calixto (2013) within the Latin American context. Accordingly, Brazilian companies provide social and environmental information that can be attributed to the existence of institutions that support and encourage the dissemination of information on sustainable practices. Another piece of possible evidence of Brazilian companies' tendency to provide such information was identified in the study, Reporting Change: Readers \& Reporters Survey 2010, which was sponsored by institutions linked to the GRI (Futerra Sustainability Communications et al., 2010). It was shown in this survey, which was conducted on four continents, that out of more than 5,000 respondents, $73 \%$ were Brazilians, 10\% were from India, 5\% were from the United States, and 12\% belonged to other countries.

\subsection{5 | "Accountability" category}

This category embodied five themes of answers. Six companies reported using their sustainability reports as tools to inform stakeholders of sustainability practices. This item was categorized as "accountability" if respondents highlighted information dissemination only. The respondents that also took into account a dialogue with stakeholders were classified as motivated by "relationship with stakeholders." A large-sized public company concluded that one of its motivations in reporting was to "disseminate practices that were questioned by universities, users, government, etc." (from Authors' research survey). Also, two respondents reported that their motivation for issuing sustainability reports was to fulfill their need to be accountable to stakeholders.

Similarly, one can use the same reasoning described as "improving the company's image," as in Brazil, there is a stakeholder-business culture that considers that the interests of stakeholders are as legitimate as those of shareholders (Legendre \& Coderre, 2013).

\subsection{6 | "Market monitoring" category}

Another motivation given by respondents was the need to monitor market practices. The themes grouped in this category were as follows:

- Reporting is an international trend,

- Reporting aligns with best market practices,

- Issuing a report is a practice of CSR, and

- Reporting is a mandatory requirement due to the Global Compact.

According to our literature review, this category-preparation of sustainability reports undertaken related to "market monitoring"-has not been examined in the literature regarding sustainability reporting. The work of Legendre and Coderre (2013) found a positive correlation between the variables size, profitability, a country's business culture, and type of industry and whether companies reported or not. A study by de Souza Campos et al. (2013) showed a positive relationship between the adoption of sustainability reporting and a company's sector.

However, it is known that the sustainability report is a global trend, and that exerts pressure on various organizations to report, possibly because of the reputational risk that failing to report could generate (Legendre \& Coderre, 2013). In addition, many authors cite the increased number of reports published as evidence of an evolving process that is likely to continue (Calixto, 2013; de Souza Campos et al., 2013; Futerra Sustainability Communications et al., 2010). This indicates that market movements can encourage new companies to issue sustainability reports.

It is noteworthy that the answer, "being a mandatory requirement due to the Global Pact" was grouped in this category. In Brazil, there is no obligation to publish sustainability reports, but in countries such as England and India, such requirements are already a reality (KPMG, 
2013), despite some studies that advocate against such an approach (Utama, 2011).

\subsection{7 | "Supporting the organization's management" category}

This category is the one with greater adherence to the mission and vision of the GRI than the others. According to the GRI, "Promoting the practice of sustainability reporting as standard, providing guidance and support to organizations" and "sustainable global economy in which organizations can responsibly and transparently measures their economic, environmental, and social impact and performance towards governance" (GRI, 2012, p. 2).

The motivations given by the organizations and included in this category are:

- Mapping of the activities performed by internationally accepted criteria,

- Comparability, periodicity, and legitimacy of the information in communication,

- Performance evaluation,

- Continuous improvement,

- Picture of the organization's economic, social, and environmental management,

- Identifying areas for improvement, and

- Standardization in reporting.

Hence, one can note the items mentioned as part of the mission and vision of the GRI. Using these responses, we conclude that a primary function of the GRI guidelines is to serve as a management tool for companies.

Despite this conclusion, some studies have criticized the effectiveness of the guidelines in this regard (Lozano \& Huisingh, 2011; Ramos et al., 2014; Utama, 2011).

A company stated that getting a picture of economic, environmental, and social management would be a reason to report. However, Lozano and Huisingh (2011) criticize the fact that the GRI guidelines are based on the concept of the Triple Bottom Line (World Commission on Environment and Development, 1987). According to the authors, information should be reported on integrated dimensions. Thus, in addition to the economic, environmental, and social dimensions, this would then provide economic and environmental dimensions integrated, environmental and social integrated, economic and social dimensions integrated, and the three integrated traditional dimensions integrated.

Another motivation that is criticized refers to the level of standardization of the information provided, which would allow a comparison of the performance results of different companies. However, one of the findings from the study, Reporting Change: Readers \& Reporters Survey (Futerra Sustainability Communications et al., 2010), sponsored by institutions linked to the GRI, is that company performance was not compared, as only $10 \%$ of the readers surveyed stated that they used the reports for comparing organizations. Utama (2011) also stated that, unlike financial reporting, the GRI guidelines do not include
EXHIBIT 1 Categories themed to group the positive and negative aspects of GRI

\begin{tabular}{|llll}
\hline Positive aspects & $\begin{array}{l}\text { Times } \\
\text { cited }\end{array}$ & Negative aspects & $\begin{array}{l}\text { Times } \\
\text { cited }\end{array}$ \\
\hline $\begin{array}{c}\text { Improving internal } \\
\text { company } \\
\text { management }\end{array}$ & 35 & Indicators & 13 \\
$\begin{array}{c}\text { Proposed guidelines } \\
\text { for report } \\
\text { elaboration }\end{array}$ & 22 & $\begin{array}{c}\text { Difficulties in the } \\
\text { proposed process }\end{array}$ & 11 \\
$\begin{array}{c}\text { Benchmarking } \\
\text { assistance }\end{array}$ & 13 & $\begin{array}{l}\text { Internal difficulties } \\
\text { Report assessment }\end{array}$ & 11 \\
\hline $\begin{array}{c}\text { Possibility of } \\
\text { legitimating }\end{array}$ & 12 & $\begin{array}{l}\text { Final report model } \\
\text { Focus on large } \\
\text { companies }\end{array}$ & 7 \\
\hline $\begin{array}{c}\text { Provides a marketing } \\
\text { tool }\end{array}$ & 3 & $\begin{array}{l}\text { Report external view } \\
\text { Use of the report as a } \\
\text { marketing tool }\end{array}$ & 3 \\
\hline
\end{tabular}

a summary that would provide the reader with an overview of the company's sustainability performance.

On the other hand, responses linked to internationally accepted criteria, frequency, performance evaluation, support in business management, and identifying areas for improvement were supported by the scientific literature, as most of the criticism focused on the fact that the organization can filter what will be reported (Brown et al., 2009; Ramos et al., 2014; Roca \& Searcy, 2012).

\subsection{Positive aspects of sustainability reporting}

In this section, we shall review the respondents' comments on the positive aspects of sustainability reporting. This section will be followed by a discussion of the negative aspects. The positive aspects identified in the GRI guidelines were grouped into five categories and the negative into eight categories, as shown in the table in Exhibit 1.

\subsection{1 | "Improving internal company management" category}

One of the respondents listed as a positive point the GRI's "encourage companies to measure the impacts generated by them" (from Authors' research survey). This response meets the vision defined by the GRI of "A sustainable global economy where organizations can measure their performance and economic, environmental, social" (GRI, 2012, p. 2).

The responses also highlighted that report preparation enables organizations to identify risks and opportunities. In addition, responses included statements to the effect that the methodology is a guide to indicators and best practices, and that the method helps organizations monitor the evolution of the indicators and the performance of the organization. One of the respondents said, "indicators can act as an internal management guide corporate sustainability" (from Authors' research survey). These responses, all of which came from large companies, show that the GRI reporting model has been used not only in the reporting process itself, but also in the sustainability management of the organizations, thus going beyond the GRI-established mission of 
"Making the practice of sustainability reporting to become standard" (GRI, 2012, p. 2). Use of the GRI reporting model as a sustainability tool may also be a factor that explains the growth rates in the adoption of the GRI model identified in the work of de Souza Campos et al., (2013) and Calixto (2013).

One response states that the reporting process "generated learning for all people involved in the publication development process" (from Authors' research survey), which represents that the GRI framework was used more as a management tool than for the report publication; according with the GRI Reporting Change: Readers \& Reporters Survey 2010 , the objectives of the organizations would be more related to increased sustainability performance than the communication and comparison of results (KPMG, 2013).

Another comment by a respondent was that the model proposed by GRI brings to the company "discipline and organization to meet deadlines and provide all the information required by company indicators" (from Authors' research survey). This reinforces the sense in which the GRI guidelines are adopted and turns the document into more of a management model than a reporting one, including as to the employees' work mode. In the same sense, another theme that emerged was the "better integration between the internal areas of the company." There are also themes that highlight improvements in management due to cultural changes, such as: "higher commitment to the company with shareholders and society," "a firm that is more accessible and favorable to dialogue," and "continuous improvement in the management."

\subsection{2 | "Proposed guidelines for report elaboration" category}

Accordingly, companies indicated positive points specifically as: methodology, using the concept of materiality, organization by theme, indicators specificity, constant improvement of indicators, addressing relevant issues, reporting a three-year history coverage, and the fact that stakeholder engagement was treated as a priority. Features grouped in this category relate more to how the GRI guidelines guide companies in reporting, rather than-for example-guaranteeing the accuracy of the information or the proper information use.

\section{Companies consider as positive the aspect of standardization and comparability that the GRI guidelines provide.}

\subsection{3 "Benchmarking assistance" category}

Companies consider as positive the aspect of standardization and comparability that the GRI guidelines provide. Twelve responding companies mentioned this point. In addition, one respondent mentioned the commitment to sustainability that annual reporting generated within the company.

If there is standardization in reporting, it is easier to compare companies, especially if the reports are published annually and one can follow the progress of the companies in which he or she has an interest. The survey data, in a way, contradict the finding that the organizations' performances would not be compared to other companies' reports. As we have already stated, less than $10 \%$ of more than 5,000 readers of the Futerra Sustainability Communications et al. (2010) report indicated that comparing the performance of organizations would be one reason to consult the reports, while having consultants compare the reports garnered the greatest response (33\%), and having investors perform comparison received 3\% (Futerra Sustainability Communications et al., 2010).

However, authors of other studies argue that standardizing the reporting through the reporting guidelines that the GRI provides would not be very relevant. Utama (2011) says that the GRI guidelines are those that come closest to offering standardization and comparability similar to financial reports, although sustainability reports do not provide summaries that would provide readers with a global view of a company's performance.

\subsection{4 "Possibility of legitimizing" category}

Many of the respondents also pointed out as positive the opportunity to legitimize the sustainability of their operations. This category groups answers related to the search for credibility (one company) and transparency (11 companies), and as previously discussed, the pursuit of transparency stems from the need to legitimize their organizations' actions toward society and the environment. This finding is based on the theory of legitimacy, according to which publishing a sustainability report would seek to build legitimacy with stakeholders by demonstrating a company's adherence to social norms and expectations (Bebbington et al., 2008).

\subsection{5 "Provides a marketing tool" category}

In this category, respondents reporting the positive attributes of sustainability listed "visibility" and "communication tool" within the theme "visibility." For example, the survey response, "promotes the company's reputation," demonstrates the use of sustainability reports as marketing tools. Among all of the positive themes revealed by the survey respondents, the concept, "provides a marketing tool" received the least number of responses. As already discussed, this indicates that, due to the criticism that sustainability reports were simply public relations tools (Haigh \& Jones, 2006), companies prefer to be discreet as to how they use their sustainability reports.

\section{3 | Negative aspects identified}

\subsection{1 | "Indicators" category}

Although the indicators proposed by the GRI have been highlighted as positive in the category "proposed guidelines for report elaboration," in this category, indicators received criticism. The aspect "no specific 
indicators for the sector" was raised, perhaps as a sign that the sector supplements (GRI, 2011) do not yet meet the needs of all companies. Furthermore, one financial services company respondent reported that the addition of its sector within the GRI's guidelines had low applicability to the company.

Other criticisms of the GRI indicators were:

- "Quantity of indicators,"

- "Some low-relevance indicators for the core business of the company," and

- "Measures used in the indicators are not customary in Brazil." (from Authors' research survey)

According to the GRI, the nonapplicability of indicators should not be a problem, as the explanation they encourage reporting organizations to include in their reports as to why they are not including information on a particular indicator is itself an important report component (GRI, 2011). However, these criticisms may mean that, in practice, companies may feel uncomfortable with providing such explanations.

\subsection{2 "Difficulties in the proposed process" category}

Although some respondents have positively pointed out the "improvement and specificity of indicators" and the use of "concept of materiality," others stated dissatisfaction with the same aspects and/or reported difficulties in use. Themes referred to as negative points grouped into this category are: "Difficulty in obtaining relevant sample of stakeholders for the development of materiality matrix," "Not very specific protocol," "Difficulty interpreting the indicators (since indicators have general descriptions, there is room for diverse understandings),"'Global report that can be generic and conflicting as to the local aspect," and "Lack of a standardized information recording procedure" (from Authors' research survey).

According to the GRI principles, the definition of what is important (what has materiality) to include in sustainability reports should be set through the mechanism of interactions between companies and stakeholders in a process that would end in the establishment of a "materiality matrix" (GRI, 2011). However, it is interesting to note that one of the responding companies claimed that its managers were having difficulty in obtaining a sample of stakeholders for the preparation of a materiality matrix. In addition to the difficulty of achieving stakeholder participation, the criticism in this category is related to the lack of standardization in the reporting process, which could result in reports that were impossible to compare across organizations. Brown et al. (2009) emphasize that given the lack of standardization of the reports, it would not be possible to compare different organizations, even within the same industry.

\subsection{3 | "Internal difficulties" category}

Unlike the former category, this classification does not reflect negative aspects related to the model itself. Instead, it points to the difficulties organizations can have when they are attempting to put the model into practice. This category displays the difficulties highlighted by Borga, Citterio, Noci, and Pizzurno (2009), which would be specific to small- and medium-sized enterprises but was possible to see could occur in large organizations as well, considering that all the respondents who commented in this category were from multinational organizations. Only two respondents did not point out negative aspects, however it is worth mentioning that their businesses are linked to sustainability practices.

Thus, this category contradicts some aspects of Borga et al. (2009), which makes problematic such theory information: "the need for currently unavailable skill levels," "financial investments in the reporting process offer no return in the short and medium term," and "limited financial resources" (from Authors' research survey) would be problems only for small- and medium-sized businesses. For example, one of the respondents from a surveyed company, which is large and publicly traded, stated, "Perhaps the main drawback is the process transformation of a large amount of information into an attractive content for stakeholders" (from Authors' research survey).

Another view is that the complexity of the sustainability reports hinders their ability to elaborate upon some of the information. According to respondents, a negative point is "complexity of the report and the poor spread throughout Brazil" (from Authors' research survey) (only English language resources were available until recently). This view is contrary to the research of de Souza Campos et al., (2013), Calixto (2013), and the study of the GRI: Reporting Change: Readers \& Reporters Survey 2010 (Futerra Sustainability Communications et al., 2010), according to which, Brazil is a country that stands out in the adoption of the GRI model reports.

\subsection{4 | "Report assessment" category}

Some of the surveyed companies criticized the classification of the GRI reports in connection with the GRI's application levels, which operate according to the number of indicators reported. Two of the companies criticized the " $\mathrm{A}$ " classification for being exclusive to companies that fulfill diverse indicators, although the indicators do not apply to all organizations. Likewise, another firm commented that the application rating level might not make sense in light of a methodology designed to identify what is relevant for specific sectors. However, the GRI guidelines emphasize that explaining the reason for the omission of an indicator counts as a reported indicator (GRI, 2012).

The respondents also claimed that the proposed classification scheme "evaluates quantity, but not quality" and "levels A, B and C are mistakenly understood as evaluation rates" (from Authors' research survey). Boiral (2013) reached a similar conclusion, finding that $90 \%$ of significant negative events had not been reported in companies' sustainability reports.

\subsection{5 | "Final report model" category}

Respondents voiced dissatisfaction with the outcome of the reporting process. Among the areas of dissatisfaction, the following reporting guidelines were identified along with some themes drawn from the survey responses indicating dissatisfaction with the reporting format. These data support Brown et al. (2009), who conducted interviews with report readers. The results those authors obtained in their own 
work indicated that the available information was not detailed enough (response of a social activist), reports had too much and unfocused information (opinion of a journalist), the number of readers was small, and the companies did not read each other's reports, given the lack of standardization.

To one company, GRI "does not require integration with financial information, which makes it a complementary aspect, not mandatory to the investors and shareholders analysis" (from Authors' research survey). In this sense, the GRI (GRI, 2013) and KPMG (KPMG, 2013) have verified a trend toward integrating sustainability reports and annual reports of companies. One of the initiatives to standardize such a novel reporting model refers to a pilot project promoted by the International Integrated Reporting Council, a partnership between the GRI and the Prince's Accounting for Sustainability Project (A4S).

\subsection{6 "Focus on large companies" category}

Several respondents commented that the model proposed by the GRI is focused on the needs of large enterprises. This category includes the subjects:

- "Lack of models for small- to medium-sized enterprises (SMEs),"

- "Business-oriented, with scarce educational applicability," and

- "Focus on large organizations." (from Authors' research survey)

Brown et al. (2009) claim that the GRI guidelines give special attention to the needs of large corporations, even though they refrain from mentioning that small- and medium-sized enterprises have not received the same attention as has been focused on the large companies' contexts. However, the GRI guidelines are clear in stating that the proposed model aims to meet the needs of organizations ranging from small businesses to multinational organizations (GRI, 2011).

\subsection{7 "External view of the reports" category}

Some respondents also claimed that not every report should be reviewed as reliable, as companies can state that they are in compliance with the guidelines regardless of whether they have received external auditing. One company stated that "some firms prepare their reports and claim to be in accordance with the guidelines, but there is no control, especially when compared to reports developed under rigid protocols" (from Authors' research survey). An auditing process could solve this problem. An assessment conducted by KPMG showed that, between the years 2002 and 2013, the percentage of audited sustainability reports increased from $30 \%$ to $60 \%$ among the 250 largest companies in the world, even though reporting was not a mandatory practice in most countries (KPMG, 2013). However, Manetti and Becatti (2009) analyzed the patterns of international sustainability auditing and concluded that such auditing should include specific guidelines for service providers. These authors also highlight the need to standardize the final reports. The GRI rewards reports with external assurance through the "+" next to the application level $(A+, B+$, and $C+)$, but this verification does requires an auditing firm. Endowing other specialized companies or a committee of stakeholders with the power to do this is needed to manage this process (GRI, 2011).
Some respondents also claimed that not every report should be reviewed as reliable, as companies can state that they are in compliance with the guidelines regardless of whether they have received external auditing.

\subsection{8 | "Use of the report as a marketing tool" category}

The categorized theme regarding responses to this negative aspect criticizes the use of sustainability reports as marketing tools, and holds that if a company is sustainable, the client/stakeholder would naturally know that, and therefore reward the organization by buying from them. However, Haigh and Jones (2006) suggest that most sustainability reports are public relations tools, and not designed to provide accountability or transparency.

\section{5 | RECOMMENDATIONS}

Among the aspects the surveyed organizations considered positive were:

- The proposed guidelines for reporting;

- The fact that the reporting model assists in performance benchmarking in sustainability;

- The possibility of legitimizing an organization's sustainability actions; and

- The ability to use their reports as marketing tools.

With the exception of the first item, the other research literature did not list these other aspects. In regard to the negative aspects, some of the points raised reflect the confirmation of previous studies, such as the criticism directed at the indicators the final report model, focus on large enterprises, the way the report is seen by readers, and the fact that some reports appear to be used in some cases only as marketing tools.

In our study, respondents revealed that companies have difficulty understanding the proposed GRI reporting model, and that there is a lack of available material translated into Portuguese. In effect, these comments provide a practical contribution for the GRI to take into account as it works on subsequent versions of its guidelines. Second, respondents also reported having difficulties in following the 
EXHIBIT 2 Suggested improvements to the current model proposed by the GRI reporting

\begin{tabular}{|c|c|c|c|}
\hline Category & Description & Suggestion & Basis \\
\hline $\begin{array}{l}\text { Final report } \\
\text { model }\end{array}$ & $\begin{array}{l}\text { Poorly appealing } \\
\text { report }\end{array}$ & $\begin{array}{l}\text { Summary that } \\
\text { offers a global } \\
\text { vision of the } \\
\text { organization }\end{array}$ & $\begin{array}{l}\text { Utama } \\
\qquad(2011)\end{array}$ \\
\hline $\begin{array}{l}\text { External } \\
\text { view of } \\
\text { the report }\end{array}$ & $\begin{array}{l}\text { Not all } \\
\text { organizations } \\
\text { are "honest" in } \\
\text { reporting }\end{array}$ & $\begin{array}{l}\text { Mandatory audit } \\
\text { and audit } \\
\text { standard } \\
\text { preparation }\end{array}$ & $\begin{array}{l}\text { Utama } \\
\qquad(2011)\end{array}$ \\
\hline $\begin{array}{l}\text { Final report } \\
\text { model }\end{array}$ & $\begin{array}{l}\text { Lack of financial } \\
\text { information } \\
\text { make an } \\
\text { additional piece } \\
\text { of analysis }\end{array}$ & $\begin{array}{l}\text { Opting for } \\
\text { integrated } \\
\text { reporting }\end{array}$ & $\begin{array}{l}\text { KPMG } \\
\qquad(2013)\end{array}$ \\
\hline $\begin{array}{l}\text { Final report } \\
\text { model }\end{array}$ & $\begin{array}{l}\text { Lack of } \\
\text { standardization }\end{array}$ & $\begin{array}{l}\text { Definition of final } \\
\text { form of report }\end{array}$ & This study \\
\hline $\begin{array}{l}\text { Report } \\
\text { assess- } \\
\text { ment }\end{array}$ & $\begin{array}{l}\text { Classification by } \\
\text { application } \\
\text { level mistaken } \\
\text { for } \\
\text { sustainability } \\
\text { performance }\end{array}$ & $\begin{array}{l}\text { New pattern of } \\
\text { development of } \\
\text { the need to } \\
\text { classify reports }\end{array}$ & This study \\
\hline $\begin{array}{l}\text { Difficulty in } \\
\text { the } \\
\text { proposed } \\
\text { process }\end{array}$ & $\begin{array}{l}\text { Undefined } \\
\text { process of } \\
\text { engagement of } \\
\text { the stakeholder }\end{array}$ & $\begin{array}{l}\text { Creating } \\
\text { standards for } \\
\text { stakeholder } \\
\text { engagement }\end{array}$ & $\begin{array}{l}\text { Siddall, } \\
\text { Grey, } \\
\text { and } \\
\text { Dyer } \\
\text { (2013) }\end{array}$ \\
\hline $\begin{array}{l}\text { Internal dif- } \\
\text { ficulties }\end{array}$ & $\begin{array}{l}\text { Lack of human } \\
\text { and financial } \\
\text { resources }\end{array}$ & $\begin{array}{l}\text { Analyzing } \\
\text { alternatives to } \\
\text { create a simpler } \\
\text { reporting and } \\
\text { effective } \\
\text { system }\end{array}$ & This study \\
\hline
\end{tabular}

guidelines, mainly due to lack of financial and intellectual resources. This could have the practical implication of developing a less rigorous reporting process than the one currently in use that would be cheaper for SMEs to follow as they learn how to develop reports. Finally, this study revealed that the responding organizations were dissatisfied that the quantity (number) of indicators reported carries more weight than the quality of the indicator data, and they request that a new reporting model be developed.

Reporting encourages the search for sustainability and CSR; however, some changes are needed to improve the effectiveness of the reporting process. Thus, some improvements to the current model proposed by the GRI are proposed in the table in Exhibit 2. Each suggestion in this Exhibit is accompanied by the analysis category section regarding the "negative" aspects that led to it, along with a brief description of the point that was criticized, and the reference to the author who made the suggestion.

Based on what has been studied, it is recommended that studies be conducted to evaluate the possibility of correcting the negative aspects of the current GRI reporting model raised in both the literature review and through the data collected during the survey documented in this paper. Furthermore, we recommend the creation of a summary chart that provides readers of sustainability reports an overview of the company's sustainability performance. In the same way, we recommend that the proposed report template not be as flexible as it currently is, both to make the reports more objective and to make them broadly comparable. Finally, we also recommend the study of strategies for encouraging the involvement of stakeholders in the process of defining the content of sustainability reports.

\section{6 | DISCUSSIONS}

Organizations considered as positive aspects: the proposed guide for reporting; the fact that the GRI model assists in the performance of benchmarking in sustainability; the possibility of legitimizing their sustainability actions; and the ability to use the sustainability report as marketing tools. Regarding the negative aspects, some of the points raised confirm the findings of previous studies, such as the criticism directed at the indicators, the final report model, a focus on large enterprises, the way the reports are seen by readers, and the fact that in some cases, reports appear to be used only as marketing tools.

Existing literatures describing positive and negatives aspects (Aras \& Crowther, 2009; Deegan, 2007; Fonseca et al., 2014; Moneva et al., 2006) explore predefined variables and relate them to companies' motivations to report. Our study explores the companies' viewpoint, without any influence, allowing us to perceive their opinions free of definitions. In other words, after collecting field data, we identified various themes. Determining how many times the organizations cited these themes, was considered relevance criteria. Indeed, this aspect is taken into account because results can show which of the themes we identified were of greater or lesser importance within the positive and negatives aspects.

Our findings support previous studies (Futerra Sustainability Communications et al., 2010), however, new concepts were also identified. Using the GRI report to value companies that were planning to make public offerings was surprising. Also, SME templates and insertion of report summaries are simple actions that the GRI can make when it is updating versions of the guidelines. Another surprising element was the lack of integration between human and financial aspects making the integration process difficult on companies' sustainability results.

\subsection{Limitations of the study}

The present study examined the GRI sustainability reporting model from the viewpoint of the reporting companies that responded to our survey. As organizations are targets of demands for better and more transparent reporting, their opinions may have had particular biases, especially because the sample is composed only of Brazilian companies. It would be interesting to conduct a study addressing a larger number of companies and using statistical analysis techniques that would allow the generalization of findings.

\subsection{Lessons learned}

At least two important lessons were learned. One is that the response percentage was low compared to the number of sample contacts. Subsequently, the answers to open questions do not transmit the full perception of responses. 


\section{ACKNOWLEDGMENTS}

The authors would like to thank José Charbel Chiappetta Jabbour and seminar participants at XXI SIMPEP - Production Engineering Symposium for the insights that improved this research. Financial support was provided by Brazilian National Council for Scientific and Technological Development (CNPq). This research was conducted as part of the dissertation of the first author under the supervision of the fifth author.

\section{ORCID}

Thiago Ferreira Quilice (D) http://orcid.org/0000-0002-2826-3238 Luciana Oranges Cezarino (iD http://orcid.org/0000-0001-5556-8275 Marlon Fernandes Rodrigues Alves (iP)

http://orcid.org/0000-0002-5543-8021

Lara Bartocci Liboni iD http://orcid.org/0000-0002-4729-7943

Adriana Cristina Ferreira Caldana (D)

http://orcid.org/0000-0003-4857-1817

\section{REFERENCES}

Aras, G., \& Crowther, D. (2009). Corporate sustainability reporting: A study in disingenuity? Journal of Business Ethics, 87(1), 279-288. Retrieved from https://link.springer.com/article/10.1007/s10551-008-9806-0

Bardin, L. (2011). Content analysis (1st ed.). São Paulo, Brazil: Edições. Retrieved from https://www.amazon.com.br/Análise-conteúdoLaurence-Bardin/dp/8562938041?tag=goog0ef-20\&smid=A1ZZFT5 FULY4LN\&ascsubtag=7868b727-dc37-4f3d-9076-6f6fbb6790e3

Baumgartner, R. J., \& Ebner, D. (2010). Corporate sustainability strategies: Sustainability profiles and maturity levels. Sustainable Development, 18(2), 76-89. Retrieved from https://onlinelibrary.wiley.com/ doi/full/10.1002/sd.447

Bebbington, J., Larrinaga, C., \& Moneva, J. M. (2008). Corporate social reporting and reputation risk management. Accounting, Auditing \& Accountability Journal, 21(3), 337-361. Retrieved from https://www. emeraldinsight.com/doi/abs/10.1108/09513570810863932

Berthelot, S., Coulmont, M., \& Serret, V. (2012). Do investors value sustainability reports? A Canadian study. Corporate Social Responsibility and Environmental Management, 19(6), 55-363. Retrieved from https:// onlinelibrary.wiley.com/doi/full/10.1002/csr.285

Boaventura, J. M. G., da Silva, R. S., \& Bandeira-De-Mello, R. (2012). Corporate financial performance and corporate social performance: Methodological development and the theoretical contribution of empirical studies. Revista Contabilidade \& Finanças, 23(60), 232245. Retrieved from http://www.scielo.br/scielo.php?pid=S1519$70772012000300008 \&$ script=sci_arttext

Boiral, O. (2013). Sustainability reports as simulacra? A counter-account of $A$ and $A+G R I$ reports. Accounting, Auditing \& Accountability Journal, 26(7), 1036-1071. Retrieved from https://www.emeraldinsight.com/ doi/abs/10.1108/AAAJ-04-2012-00998

Borga, F., Citterio, A., Noci, G., \& Pizzurno, E. (2009). Sustainability report in small enterprises: Case studies in Italian furniture companies. Business Strategy and the Environment, 18(1), 162-176. Retrieved from https://onlinelibrary.wiley.com/doi/full/10.1002/bse.561

Brown, H. S., De Jong, M., \& Levy, D. L. (2009). Building institutions based on information disclosure: Lessons from GRI's sustainability reporting. Journal of Cleaner Production, 17(6), 571-580. Retrieved from https://www.sciencedirect.com/science/article/pii/S0959652608 003211

Calixto, L. (2013). A divulgação de relatórios de sustentabilidade na América Latina: Um estudo comparativo. Revista de Admin- istração, 48(4), 828-842. Retrieved from https://www.science direct.com/science/article/pii/S0080210716303119

Carnevale, C., \& Mazzuca, M. (2014). Sustainability report and bank valuation: Evidence from European stock markets. Business Ethics: A European Review, 23(1), 69-90. Retrieved from https://online library.wiley.com/doi/full/10.1111/beer.12038

Caron, M. A., \& Turcotte, M. F. B. (2009). Path dependence and path creation. Framing the extra-financial information market for a sustainable trajectory. Accounting, Auditing \& Accountability Journal, 22(2), 272-297. Retrieved from https://www.emeral dinsight.com/doi/abs/10.1108/09513570910933979

de Souza Campos, L. M., Sehnem, S., Oliveira, M. D. A. S., Rossetto, A. M., Coelho, A. L. D. A. L., \& Dalfovo, M. S. (2013). Relatório de sustentabilidade: Perfil das organizações brasileiras e estrangeiras segundo o padrão da Global Reporting Initiative. Gestão \& Produção, 20(4), 913-926. Retrieved from http://www.scielo.br/pdf/ gp/2013nahead/aop_gp0954_ao.pdf

Deegan, C. (2002). Introduction: The legitimising effect of social and environmental disclosures-a theoretical foundation. Accounting, Auditing \& Accountability Journal, 15(3), 282-311. Retrieved from https:// www.emeraldinsight.com/doi/abs/10.1108/09513570210435852

Deegan, C. (2007). Organizational legitimacy as a motive for sustainability reporting. In D. Bibassier \& J. Unerman (Eds.), Sustainability accounting and accountability (pp. 127-149). London, England; New York, NY: Routledge. Retrieved from https://www.taylorfrancis. com/books/e/9781136714016

Dincer, B. (2011). Do the shareholders really care about corporate social responsibility? International Journal of Business and Social Science, 2(10), 71-77. Retrieved from https://www.ijbssnet. com/journals/Vol.\%202_No._10\%3B_June_2011/9.pdf

Fifka, M. (2013). Corporate responsibility reporting and its determinants in comparative perspective: A review of the empirical literature and a meta-analysis. Business Strategy and the Environment, 22(1), 1-35. NOTE: Scholar Google gave the date as 2013, although it was first published in 2011. Retrieved from https://onlinelibrary. wiley.com/doi/full/10.1002/bse.729

Fonseca, A., McAllister, M., \& Fitzpatrick, P. (2014). Sustainability reporting among mining corporations: A constructive critique of the GRI approach. Journal of Cleaner Production, 84, 70-83. Retrieved from https://www.sciencedirect.com/science/article/pii/S0959652612006 440

Futerra Sustainability Communications, KPMG, \& Sustainability. (2010). Reporting change: Readers \& reporters survey 2010. Retrieved from http://s10458.pcdn.co/wp-content/uploads/2016/09/reporting_change .pdf

Gray, R. (2001). Thirty years of social accounting, reporting and auditing: What (if anything) have we learnt? Business ethics: A European review, 10(1), 9-15. Retrieved from https://onlinelibrary.wiley.com/ doi/abs/10.1111/1467-8608.00207

Gray, R., \& Milne, M. J. (2002). Sustainability reporting: Who's kidding whom? Chartered Accountants Journal of New Zealand, 81(6), 66-70.

Gray, R. H., Owen, D. L., \& Adams, C. (1996). Accounting and accountability, changes and challenges in corporate social and environmental reporting. Hemel Hempstead, England: Prentice Hall.

Global Reporting Initiative (GRI). (2011). Diretrizes para relatório de sustentabilidade: Versão 3.1. Amsterdam, the Netherlands: Author.

Global Reporting Initiative (GRI). (2012). Pontos de partida relatórios de sustentabilidade da GRI: Quanto vale essa jornada? Amsterdam, the Netherlands: Author. Retrieved from https://www.globalreporting. org/information/about-gri/Pages/default.aspx

Global Reporting Initiative (GRI). (2013). The sustainability content of integrated reports: A survey of pioneers. Amsterdam, the Netherlands: Author. 
Haigh, M., \& Jones, M. T. (2006). The drivers of corporate social responsibility: A critical review. Retrieved from https://citeseerx.ist.psu edu/viewdoc/download?doi=10.1.1.528.6764\&rep=rep1\&type=pdf

Illingworth, D. (2004). New reporting models for business: Who needs them? Measuring Business Excellence, 8(2), 4-8. Retrieved from https:// www.emeraldinsight.com/doi/abs/10.1108/13683040410539373

Isaksson, R., \& Steimle, U. (2009). What does GRI-reporting tell us about corporate sustainability? The TQM Journal, 21(2), 168-181. Retrieved from https://www.emeraldinsight.com/doi/abs/10.1108/175427309 10938155

KPMG. (2013). The KPMG survey of corporate responsibility reporting 2013. Retrieved from https://www.kpmg.com/Global/en/Issues AndInsights/ArticlesPublications/corporate-responsibility/Documents/ corporate-responsibility-reporting-survey-2013.pdf

Legendre, S., \& Coderre, F. (2013). Determinants of GRI G3 application levels: The case of the Fortune Global 500. Corporate Social Responsibility and Environmental Management, 20(3), 182-192. Retrieved from https://onlinelibrary.wiley.com/doi/full/10.1002/csr.1285

Lozano, R., \& Huisingh, D. (2011). Inter-linking issues and dimensions in sustainability reporting. Journal of Cleaner Production, 19(2), 99-107. https://doi.org/10.1016/j.jclepro.2010.01.004

Manetti, G., \& Becatti, L. (2009). Assurance Services for Sustainability Reports: Standards and Empirical Evidence. Journal of Business Ethics, 87(S1), 289-298. Retrieved from https://link.springer.com/article/10.1007/s10551-008-9809-x

Mc Elroy, M. W., Jorna, R. J., \& Van Engelen, J. (2008). Sustainability quotients and the social footprint. Corporate Social Responsibility and Environmental Management, 15(4), 223-234. Retrieved from https:// onlinelibrary.wiley.com/doi/full/10.1002/csr.164

Moneva, J. M., Archel, P., \& Correa, C. (2006). GRI and the camouflaging of corporate unsustainability. Accounting forum. Elsevier, 30(2), 121-137. Retrieved from https://www.sciencedirect.com/science/ article/pii/S0155998206000159

Morhardt, J. E. (2009). General disregard for details of GRI human rights reporting by large corporations. Global Business Review, 10(2), 141158. Retrieved from https://journals.sagepub.com/doi/abs/10.1177/ 097215090901000201

Moseñe, J. A., Burritt, R. L., Sanagustín, M. V., Moneva, J. M., \& Tingey-Holyoak, J. (2013). Environmental reporting in the Spanish wind energy sector: An institutional view. Journal of Cleaner Production, 40, 199-211. Retrieved from https://www.sciencedirect. com/science/article/pii/S0959652612004453

Patten, D. M. (2002). The relation between environmental performance and environmental disclosure: A research note. Accounting, Organizations and Society, 27(8), 763-773. Retrieved from https://www. sciencedirect.com/science/article/pii/S0361368202000284

Ramos, T. B., Martins, I. O., Martinho, A. P., Douglas, C. H., Painho, M. \& Caeiro, S. (2014). An open participatory conceptual framework to support State of the Environment and Sustainability Reports. Journal of Cleaner Production, 64, 158-172. Retrieved from https://www. sciencedirect.com/science/article/pii/S0959652613005787

Reynolds, M., \& Yuthas, K. (2008). Moral discourse and corporate social responsibility reporting. Journal of Business Ethics, 78(1-2), 47-64. Retrieved from https://link.springer.com/article/10.1007/ s10551-006-9316-x

Roca, L. C., \& Searcy, C. (2012). An analysis of indicators disclosed in corporate sustainability reports. Journal of Cleaner Production, 20(1), 103-118. Retrieved from https://www.sciencedirect.com/science/ article/pii/S0959652611002812

Samuel, V. B., Agamuthu, P., \& Hashim, M. A. (2013). Indicators for assessment of sustainable production: A case study of the petrochemical industry in Malaysia. Ecological Indicators, 24, 392-402. Retrieved from https://www.sciencedirect.com/science/article/pii/S1470160X1200 2828

Siddall, E., Grey, T., \& Dyer, M. (2013). Indicators and stakeholder engagement: a Dublin case study. Proceedings of the ICE - Engineering Sustainability, 166(2), 85-97. Retrieved from https://www.icevirtuallibrary.com/doi/10.1680/ensu.12.00004

Utama, S. (2011). An evaluation of support infrastructures for corporate responsibility reporting in Indonesia. Asian Business \& Management, 10(3), 405-424. Retrieved from https://link.springer.com/article/ 10.1057/abm.2011.10

World Commission On Environment and Development. (1987). Our common future. Oxford, England: Oxford University Press.

\section{AUTHORS' BIOGRAPHIES}

Thiago Ferreira Quilice is a lecturer at the Federal Institute of Education, Science and Technology of Minas Gerais and a PhD candidate in Business Administration at the Federal University of Minas Gerais. He holds an MSc degree in business administration from the University of Sao Paulo. His research focuses on corporate social responsibility, innovation, and smart cities.

Luciana Oranges Cezarino is an assistant professor at the Federal University of Uberlândia. She holds a PhD in management from the University of São Paulo. Her research focuses on organizational sustainability, green supply chain, systemic vision, and interdisciplinarity applied to learning processes.

Marlon Fernandes Rodrigues Alves is a lecturer at the Federal Institute of Education, Science and Technology of São Paulo and a PhD candidate in business administration at the University of Sao Paulo. His research focuses on dynamic capabilities, managerial cognition, innovation, and organizational sustainability.

Lara Bartocci Liboni is an associate professor at the University of Sao Paulo. She holds a PhD in management from the University of São Paulo. Her research focuses on organizational sustainability, green supply chain, systemic vision, dynamic capabilities, and management education.

Adriana Cristina Ferreira Caldana is an assistant professor at the University of Sao Paulo. She holds a PhD in psychology from the University of São Paulo. Her research focuses on human resources, organizational sustainability, executive education for sustainability, and stakeholders' management.

How to cite this article: Quilice TF, Cezarino LO, Alves MFR, Liboni LB, Caldana ACF. Positive and negative aspects of GRI reporting as perceived by Brazilian organizations. Environ Qual Manage. 2018;27:19-30. https://doi.org/10.1002/tqem.21543 